\title{
DUAL RECIPROCITY BOUNDARY ELEMENT METHOD (DRBEM) DENGAN PREDIKTOR-KOREKTOR UNTUK MASALAH INFILTRASI STASIONER PADA SALURAN DENGAN LAPISAN IMPERMEABEL DENGAN ROOT WATER UPTAKE
}

\author{
Irma Novalinda Nasution \\ Program Studi Pendidikan Fisika, Universitas Graha Nusantara \\ email: irma.novalinda81@gmail.com
}

\begin{abstract}
This study aims to discussed about Dual Reciprocity Boundary Element Method (DRBEM) with a predictor-corrector for steady infiltration problems with impermeabel layer with root water uptake in homogeneous soils. Steady infiltration in homogeneous soils is governed by Richard equation. This equation is transformed using a set of transformation including Khirchoff, dimensionless variabels and dimensionless parameters into a type of modified Helmholtz equation. Furthermore with DRBEM, numerical solution of modified Helmholtz equation obtained. The proposed method is tested on problem involved infiltration from rectangular and trapezoidal channels with impermeabel layer with root water uptake.
\end{abstract}

Keyword : infiltration, root water uptake, modified Helmholtz equation, Richard equation, DRBEM.

\begin{abstract}
Abstrak
Penelitian ini bertujuan untuk membahas tentang Dual Reciprocity Boundary Element Method (DRBEM) dengan prediktor-korektor untuk masalah infiltrasi stasioner pada saluran dengan lapisan impermeabel disertai root water uptake pada jenis tanah homogen. Infiltrasi stasioner pada tanah homogen dibangun dari Persamaan Richard. Persamaan Richard ini kemudian ditransformasikan dengan menggunakan transformasi Khirchoff, variabel tak berdimensi dan konstanta tak berdimensi menjadi Persamaan Helmholtz termodifikasi. Selanjutnya dengan menggunakan DRBEM, solusi numerik dari Persamaan Helmholtz termodifikasi diperoleh. Metode tersebut digunakan untuk menyelesaikan masalah infiltrasi pada saluran rectangular dan trapezoidal dengan lapisan impermeabel disertai proses root water uptake.
\end{abstract}

Kata kunci : infiltrasi, root water uptake, Persamaan Richard, Persamaan Helmholtz termodifikasi, DRBEM.

\section{PENDAHULUAN}

Menurut Peraturan Pemerintah No. 20 (2006) tentang Irigasi, irigasi adalah suatu badan uasaha penyediaan, pengaturan dan pembuangan air irigasi untuk menunjang pertanian yang jenisnya meliputi irigasi permukaan, irigasi rawa, irigasi air bawah tanah, irigasi pompa dan irigasi tambak. Pemberian air irigasi melalui permukaan tanah memiliki keuntungan yaitu perawatan yang mudah dan biaya yang murah sehingga banyak petani menggunakan sistem ini. Penelitian ini dilakukan pada irigasi melalui permukaan tanah dengan sistem irigasi alur. Sistem irigasi alur adalah sistem irigasi permukaan dimana lahan pertanian yang akan dialiri dibagi menjadi petak yang kecil (gundukan) dan air dialirkan melalui parit-parit diantara gundukan. 
Penelitian ini dilakukan pada irigasi melalui permukaan tanah dengan sistem irigasi alur. Sistem irigasi alur adalah sistem irigasi permukaan dimana lahan pertanian yang akan dialiri dibagi menjadi petak yang kecil (gundukan) dan air dialirkan melalui parit-parit diantara gundukan.

Seiring dengan perkembangan ilmu pengetahuan, banyak penelitian yang sudah dilakukan berkaitan dengan infiltrasi pada saluran irigasi. Salah satunya adalah penelitian Batu (1978) tentang Steady Infiltration from Single and Periodic Strip Sources. Solekhudin et al.,(2012), bentuk saluran irigasi yang digunakan adalah flat dan dapat diselesaikan secara analitik. Akan tetapi, umumnya saluran irigasi yang sering digunakan berbentuk trapesium, rectangular. Penyelesaian analitik untuk saluran selain flat sangat sulit dilakukan. Untuk itu digunakan pendekatan penyelesaian yaitu menggunakan metode numerik Dual Reciprocity Boundary Element Method (DRBEM).

\section{Root Water Uptake}

Pada irigasi, air diharapkan dapat diserap oleh tumbuhan. Proses ini disebut dengan root water uptake. Root water uptake merupakan proses yang sangat penting dan terjadi di bawah permukaan tanah. Fungsinya adalah mengontrol fluks air di bawah tanah. Vrugt (2001a) membangun model root water uptake untuk dua dimensi sebagai berikut

$$
\beta(X, Z)=\left(1-\frac{L+D-X}{X m}\right)\left(1-\frac{Z}{Z m}\right) e^{-\left(\frac{p Z}{Z m}\left|Z^{*}-Z\right|+\frac{p x}{X m}\left|X^{*}-(L+D-X)\right|\right)}
$$

dengan $\beta(X, Z)$ adalah distribusi akar spatial dua dimensi, $\mathrm{X}$ adalah jarak tengah saluran pada sumbu $X, L$ adalah setengah dari lebar saluran, $D$ adalah setengah dari lebar permukaan tanah diluar saluran, $\mathrm{Z}_{\mathrm{m}}$ adalah kedalaman akar dan $\mathrm{p}_{\mathrm{X}}, \mathrm{p}_{\mathrm{Z}}, \mathrm{X}^{*}$ dan $\mathrm{Z}^{*}$ adalah parameter empiris. Pada penelitian ini dianggap distribusi ruang akar berada pada bidang XZ. Tanaman ditanam pada permukaan tanah diantara dua saluran dengan jarak yang sama. Jika pusat sistem koordinat kartesius berada pada pusat saluran, maka tanaman berada pada jarak (L+D) dari pusat sistem koordinat. Daerah akar diasumsikan berbentuk rectangular dengan lebar $2 \mathrm{X}_{\mathrm{m}}$ dan kedalaman $\mathrm{Z}_{\mathrm{m}}$. Model distribusi ruang akar dua dimensi ditunjukkan pada Gambar 1 .

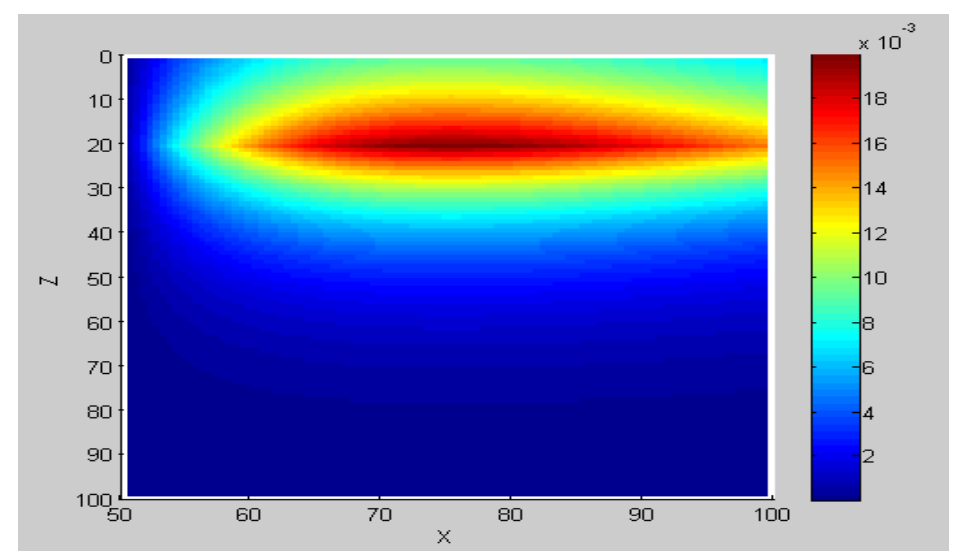

Gambar 1. Distribusi akar spatial dua dimensi $\beta(X, Z)$ 
Root water uptake $\mathrm{S}$ bergantung pada potensial kumulatif root water uptake Vrugt (2001b), suction potensial, dan tekanan salinitas. Pada penambahan tekanan air, root water uptake tereduksi ketika konsentrasi larutan garam melebihi nilai ambang batas, sehingga root water uptake dimodelkan sebagai berikut

$$
S(X, Z, \psi, \pi)=\gamma(\psi, \pi) \operatorname{Sm}(X, Z)
$$

dengan $\Upsilon$ merupakan fungsi tekanan salinitas dan air tak berdimensi , $\psi$ adalah suction potensial dan $\pi$ adalah osmotic head. Maka model root water uptake yang digunakan adalah yang disederhanakan dengan mengabaikan osmotic head $(\pi)$ sehingga model menjadi

$$
S(X, Z, \psi)=\gamma(\psi) \operatorname{Sm}(X, Z)
$$

Persamaan (3) disebut sebagai model untuk root water uptake.

\section{Formulasi Masalah}

Penelitian ini akan menggunakan DRBEM untuk menyelesaikan masalah infiltrasi stasioner pada beberapa jenis saluran periodik dengan root water uptake. Jenis saluran irigasi yang akan dibandingkan adalah

1. Saluran rectangular dengan lapisan impermeabel

2. Saluran trapezoidal dengan lapisan impermeabel

Selanjutnya akan ditentukan domain dari masing-masing saluran irigasi. Dalam menentukan domain saluran irigasi perlu diberikan asumsi-asumsi tertentu yaitu

1. Panjang penampang masing-masing saluran irigasi adalah sama yaitu $2 \mathrm{~L}$.

2. Jarak antar saluran adalah sama yaitu $2 \mathrm{D}$ atau jarak antar titik tengah saluran adalah sama yaitu $2(\mathrm{~L}+\mathrm{D})$.

3. Saluran samgat panjang.

4. Saluran selalu penuh dengan air.

5. Laju infiltrasi air/besar flux masuk pada permukaan saluran irigasi adalah konstan, yakni sebesar vo.

6. Tidak ada infiltrasi pada permukaan tanah diluar saluran irigasi.

Dengan sifat simetris, dapat didefenisikan domainnya adalah sebuah daerah semi infinite $0 \leq X \leq L+D$ dan $Z \geq 0$ yang dinyatakan dengan $R$.

\section{Persamaan Fundamental}

Persamaan Richard berbentuk Persamaan Differensial Parsial Non Linier yang merepresentasikan perpindahan air berdimensi dua dalam tanah tidak jenuh. Secara matematis dapat ditulis sebagai berikut

$$
\frac{\partial}{\partial X}\left(K(\psi) \frac{\partial \psi}{\partial X}\right)+\frac{\partial}{\partial Z}\left(K(\psi) \frac{\partial \psi}{\partial Z}\right)-\frac{\partial K}{\partial Z}=S(X, Z, \psi)
$$

dengan $\mathrm{K}(\theta)$ adalah hydraulic conductivity yang berdimensi $\mathrm{L} / \mathrm{T}, \quad \psi$ adalah suction potensial yang berdimensi $\mathrm{L}$ dan $\mathrm{S}$ adalah fungsi root water uptake. 
Persamaan (4) berbentuk persamaan diferensial non linier yang penyelesaiannya sangat sulit, sehingga diperlukan transformasi untuk mengubah Persamaan (4) kebentuk persamaan yang lebih mudah diselesaikan. Salah satunya dengan transformasi yang diberikan oleh Kirchoff dan menggunakan model eksponensial konduktifitas hidraulik yang diberikan oleh Garner untuk mengubah Persamaan Richard ke bentuk Persamaan Helmholtz (Solekhudin, 2013).

Terdapat empat tahapan dalam transformasi ini, yaitu:

1. Transformasi Khirchoff menggunakan rumus

$$
\Theta=\int_{-\sim}^{\psi} K(s) d s
$$

dengan $\Theta$ adalah Matrik Flux Potential (MFP) .

2. Model eksponensial dari konduktifitas hidraulik yang didefenisikan oleh

$$
K=K_{0} e^{\alpha \psi}, \alpha>0
$$

dengan $\alpha$ adalah sebuah parameter dan $\mathrm{K}_{0}$ adalah konduktifitas hidraulik pada tanah jenuh.

3. Digunakan variabel tak berdimensi

$$
x=\frac{\alpha}{2} X, \quad z=\frac{\alpha}{2} Z, \Phi=\frac{\pi \Theta}{v o L}, u=\frac{2 \pi}{v o \alpha L} U, v=\frac{2 \pi}{v o \alpha L} V, f=\frac{2 \pi}{v o \alpha L}
$$

dengan vo adalah flux awal dan $\mathrm{L}$ adalah setengah panjang saluran irigasi.

4. Digunakan konstanta tak berdimensi

$$
\begin{gathered}
l t=\frac{\alpha}{2} L t ; \quad x=\frac{\alpha}{2} X m ; \quad z_{m}=\frac{\alpha}{2} Z m ; x^{*}=\frac{\alpha}{2} X ; z^{*}=\frac{\alpha}{2} Z^{*} ; \quad p_{x}=\frac{\alpha}{2} p_{z} \\
a=\frac{\alpha}{2} L ; \quad b=\frac{\alpha}{2}(L+D)
\end{gathered}
$$

Menggunakan empat langkah tersebut, Persamaan Richard dapat ditransformasikan menjadi

$$
\frac{\partial^{2} \phi}{\partial x^{2}}+\frac{\partial^{2} \phi}{\partial z^{2}}-\phi=\gamma^{*}(\phi) s^{*}(x, z) e^{-z}
$$

Persamaan (9) inilah yang disebut sebagai Persamaan Helmholtz termodifikasi, yang merepresentasikan infiltrasi air pada saluran irigasi jenuh. Selain itu, diperoleh transformasi dari flux normal

$$
f=-e^{z}\left(\partial \phi / \partial n-\phi n_{2}\right)
$$

dan diperoleh definisi turunan normal,

$$
\frac{\partial \phi}{\partial n}=\phi n_{2}-e^{-z} f
$$


Domain dalam model ini adalah daerah semi tak terhingga $\mathrm{R}$, sedangkan penyelesaian menggunakan DRBEM mensyaratkan domain harus tertutup dan terbatas. Sehingga perlu dilakukan pembatasan domain dengan mengambil $\mathrm{z}=\mathrm{c}$, untuk suatu c bilangan real positif. Fluks pada permukaan saluran adalah vo dan besar fluks tak berdimensi adalah $2 \pi / \alpha \mathrm{L}$, sehingga diperoleh

$$
\frac{\partial \phi}{\partial n}=\phi n_{2}+\frac{2 \pi}{\alpha L} e^{-z}, \quad \text { pada } C_{1}
$$

Tidak adanya fluks pada permukaan tanah di luar saluran dan sepanjang $\mathrm{X}=0$ dan $\mathrm{X}=\mathrm{L}+\mathrm{D}$, mengakibatkan

$$
\begin{array}{ll}
\frac{\partial \phi}{\partial n}=-\phi, & \text { pada } C_{2}, \\
\frac{\partial \phi}{\partial n}=0, & \text { pada } C_{3} \\
\frac{\partial \phi}{\partial n}=0, & \text { pada } C_{4}
\end{array}
$$

Berdasarkan asumsi tidak ada perubahan MFP pada kedalaman yang cukup dalam, diperoleh

$$
\frac{\partial \phi}{\partial n}=-\phi, \quad \text { pada } C_{5}
$$

Dual Reciprocity Boundary Element Method (DRBEM) digunakan untuk mencari solusi numerik Persamaan (9) dengan syarat batas yang telah diberikan pada Persamaan (12)-(16). Pada tahap selanjutnya, mencari solusi numerik dengan DRBEM dibutuhkan suatu persamaan integral yang disebut Persamaan Integral Batas yaitu

$$
\begin{aligned}
& \lambda(\xi, \eta) \phi(\xi, \eta)=-\int_{C_{1}} \Phi(x, z ; \xi, \eta)\left(\frac{2 \pi}{\alpha L} e^{-z}+n_{2}^{(k)} \phi(x, z)\right) d s(x, z) \\
& \int_{C_{2} \cup C_{5}} \phi(x, z)\left(\frac{\partial \Phi(x, z ; \xi, \eta)}{\partial n}+\Phi(x, z ; \xi, \eta)\right) d s(x, z) \\
&+\int_{C_{2 \cup C_{5} \cup C_{4}} \phi(x, z) \frac{\partial \Phi(x, z ; \xi, \eta)}{\partial n} d s(x, z)} \\
&+\iint_{R} \Phi(x, z ; \xi, \eta)\left[\phi(x, z)+\gamma^{*}(\phi) s^{*}(x, z) e^{-z}\right] d x d z
\end{aligned}
$$

dengan

$$
\Phi(x, z ; \xi, \eta)=\frac{1}{2 \pi} \ln \sqrt{\left[(x-\xi)^{2}+(z-\eta)^{2}\right]}
$$

adalah solusi fundamental Persamaan Laplace dua dimensi. 


\section{Hasil dan Pembahasan}

Penelitian ini menggunakan DRBEM untuk menyelesaikan masalah infiltrasi air pada saluran dengan lapisan impermeabel dengan root water uptake dan dipilih jenis tanah Pima Clay Loam (PCL). Untuk jenis tanah PCL, nilai $\alpha$ dan Ko masingmasing adalah $0.014 \mathrm{~cm}^{-1}$ dan $9.9 \mathrm{~cm} /$ day. Besarnya fluks yang masuk pada permukaan saluran infiltrasi vo sebesar $75 \%$ dari nilai Ko. Nilai Tpot atau potensial transpirasi tanaman yang digunakan adalah $0.4 \mathrm{~cm} / \mathrm{hari}$.

Pada DRBEM, banyaknya segmen garis (N) dan titik interior (M) berpengaruh terhadap keakuratan solusi numerik yang dihasilkan. Berikut diberikan banyaknya $\mathrm{N}$ dan $\mathrm{M}$ pada masing-masing saluran:

a. Saluran rectangular dengan lapisan impermeabel diberikan $\mathrm{N}=208$ dan $\mathrm{M}=609$.

b. Saluran trapezoidal dengan lapisan impermeabel diberikan $N=209$ dan $M=609$.

Selanjutnya, direpresentasikan Matriks Fluks Potensial (MFP) tak berdimensi, $\Phi$ dari 2 saluran yang berbeda. Nilai $\Phi$ untuk saluran dengan proses root water uptake pada grafik ditunjukkan dengan garis penuh, sementara untuk masalah tanpa root water uptake pada grafik ditunjukkan dengan garis putus-putus.

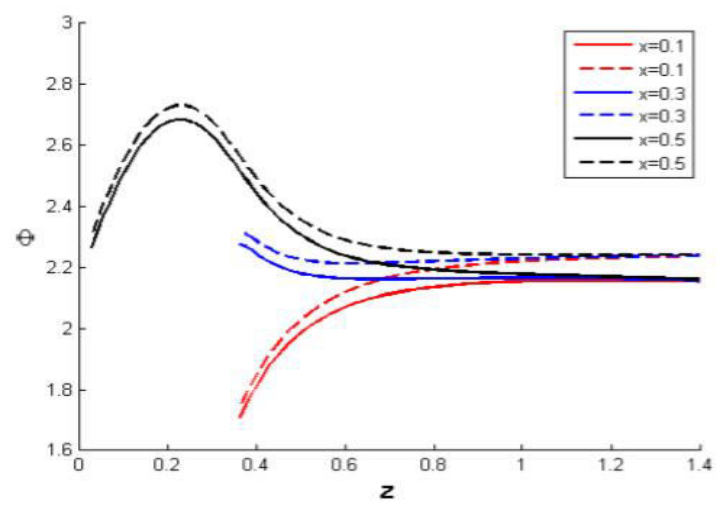

Gambar 2. Nilai MFP tak berdimensi saluran rectangular dengan lapisan impermeabel.

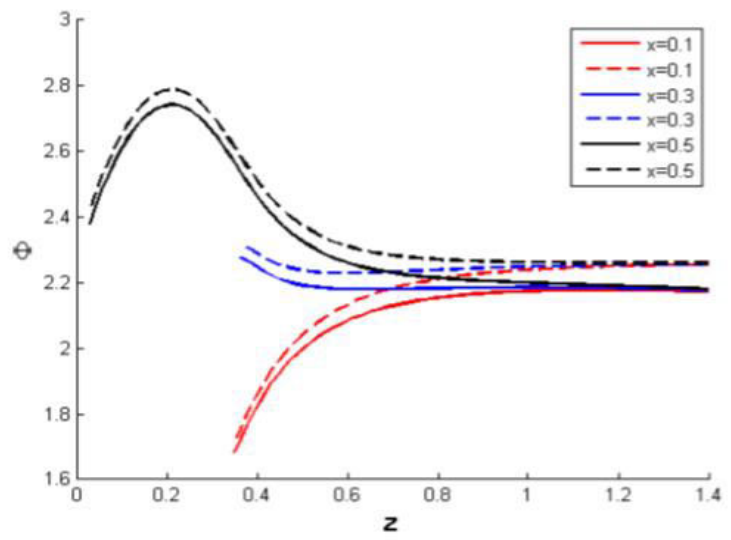

Gambar 3. Nilai MFP tak berdimensi saluran trapesium dengan lapisan impermeabel.

Terlihat pada gambar 3 untuk kedua saluran tersebut, pada $\mathrm{x}=0.1$ nilai $\Phi$ naik seiring bertambahnya kedalaman tanah sampai fase kekonvergenannya. Hal ini disebabkan karena adanya lapisan impermeabel pada saluran. 
Selanjutnya, pada $\mathrm{x}=0.5$ yang terletak tidak di bawah saluran, nilai $\Phi$ naik pada kedalaman tertentu dan turun pada kedalaman tertentu hingga mencapai fase kekonvergenannya. Hal ini menunjukkan kandungan air lebih rendah di daerah pangkal dibawah permukaan tanah dibandingkan dengan daerah yang lebih dalam dan selanjutnya turun seiring bertambahnya kedalaman tanah.

\section{Kesimpulan}

Berdasarkan hasil penelitian ini, DRBEM dengan metode prediktor-korektor dapat diaplikasikan pada masalah infiltrasi stasioner pada saluran rectangular dan trapezoidal dengan lapisan impermeabel yang disertai dengan proses root water uptake pada jenis tanah homogen. DRBEM digunakan untuk mendapatkan solusi numerik dari Persamaan Helmholtz termodifikasi. Solusi untuk infiltrasi tanpa proses root water uptake juga diberikan, solusi ini digunakan untuk memprediksi nilai fungsi reaksi tekanan air. Kemudian solusi masalah infiltrasi yang disertai dengan proses root water dengan yang tanpa proses root water uptake dibandingkan. Dari hasil yang diperoleh mengindikasikan bahwa kandungan air dibawah saluran mulai naik pada kedalaman tertentu karena adanya lapisan impermeabel dan kandungan air pada tanah menurun karena penyerapan air oleh akar tanaman.

\section{Daftar Pustaka}

Batu, V. 1978. Steady Infiltration from Single and Periodic Strip Source. Soil Sci. Soc. Am. J. 42, pp.544-549.

Solekhudin, Imam. 2013. Dual Reciprocity Boundary Element Methods for Water Infiltration Problem In Irrigation. PHD Thesis. National Institut of Education Nanyang Technological University.

Solekhudin, Imam dan Ang, K.C. 2012. A DRBEM with a predictor-corrector scheme for steady infiltration from periodic channels with root-water uptake. Electronic Jurnal of Boundary Element.

Republik Indonesia. 2006. Peraturan Pemerintah Republik Indonesia No. 26 Tentang Irigasi Indonesia.

Vrugt, J.A., 2001a. One-, two-, and three-dimensional root water uptake function for transient modelling. Water Resources Research. Vol. 37. No.10. Pages 24572470.

2001b. Calibration of a Two-Dimensional Root Water Uptake Model. Water Resources Research. Vol.65.No.4. Pages 1027-1037. 